\title{
Stem Cells and Stem Cells / Precursors-Derived Extracellular Vesicles in Heart Failure: What is better for Cardiac Regeneration?
}

\author{
Alexander Berezin* \\ Consultant of Therapeutic Unit, Internal Medicine Department, State Medical University for Zaporozhye
}

*Corresponding author: Alexander Berezin, Professor, MD, PhD, Consultant of Therapeutic Unit, Internal Medicine Department, State Medical University for Zaporozhye, 26, Mayakovsky Av, Zaporozhye, Postcode 69035, Ukraine, Tel: +38 0612894585 ; Fax: +38 0612894585; E-mail: aeberezin@gmail.com

\begin{abstract}
:
Heart Failure (HF) is a major factor contributing to premature death in patients with established Cardiovascular (CV) disease. Current cell therapies of HF based on at least two different approaches, in which stem cell transplantation and Extracellular Vesicles (EV) received from pre-treated cells, were used. Although in HF restoring cardiac function aimed to improve survival is a target of cell therapy, it is not yet yielded whether isolated EVs from circulating progenitor cells, induced Pluripotent Stem Cells (iPSCs), human embryonic stem cells-derived CV progenitors (HESC-Pg) would be effective translators of reparative signals for cardiac repair. The editorial depicts the role of different cell strategies in HF. It has emphasized lack of strong evidence of clinical advantages implanted EVs to human cells to iPSCs in HF requires comparison in large clinical trials.
\end{abstract}

Keywords: Heart failure; Cell therapies; Human stem cells; Human progenitors; Progenitor cell-derived extra vesicles

\section{Introduction}

Heart Failure (HF) remains a potent fatal end-stage of the natural evolution of numerous cardiac diseases with complex and uncertain pathophysiology mechanisms ${ }^{[1,2]}$. There is evidence that the impaired reparative processes in myocardium affecting cardiac myocytes loss, extracellular matrix remodeling, vasculogenesis, neovascularization, abnormal switch-on of metabolic fetal genes, co-regulation of (pro)-oncogenes, overexpression of oxidative molecules and others could be accompanied with progression of HF regardless of its etiologies ${ }^{[3-5]}$. The Wide range of preclinical and clinical studies depicted the innate molecular pathways of the disease that may be used as therapeutic targets for novel agents recovering reparative capacity of the myocardium in $\mathrm{HF}^{[6-8]}$.

Extracellular vesicles (EV) are generally defined as intracellular originated particles shaded from the plasma membrane (micro particles) and released after the fusion of the plasma membranes or formed from endosomes (exosomes) with different size ranges that are usually $100 \mathrm{~nm}$ and less ${ }^{[9]}$. EVs are secreted by numerous cells with different origin due to different signaling mediators and may unleash favorable effects on cardiac reparation by modulation of the metabolism of target cells by transferring signal proteins, growth factors and various genomic materials ${ }^{[10]}$. EVs acting as cargo of secreted factors are powerful regulator of cell-to-cell communications. Moreover, EVs are a component of cell secretom that is under direct and indirect influences of various epigenetic factors (pro-inflammatory cytokines, free radicals, micro RNAs, etc.), which co-expressed in HF and are able to change a capability of EVs to repair tissues ${ }^{[4,9]}$. Indeed, lowered functionality of progenitor cells and weak abilities to release EVs with reparative capacity in HF is well established, while the data regarding repair activity of other cells, including stem cells, mature cells with different origin are limited ${ }^{[9]}$. This phenomenon became to be known as progenitor cell dysfunction and it's associated with impaired circulating EV immune phenotypes due to imbalance between EVs released from activated and apoptotic precursors ${ }^{[7]}$. Development and progression of HF strongly associated with elevation of circulating EVs shaping from various populations of the cells, including stem cells, progenitor cells and mature endothelial cells, some

\section{Received date: February 25, 2018 \\ Accepted date: March 20, 2018 \\ Publish date: March 26, 2018}


Citation: Berezin, A. Stem Cells and Stem Cells / Precursors-Derived Extracellular Vesicles in Heart Failure: What is better for Cardiac Regeneration? (2018) J Stem Cell Regen Biol 3(1): 1- 3.

resident cells, mononuclear cells, adipocytes, cardiac myocytes, that reflects a tenderness of reparative processes and therefore a signature of the EVs may be a marker of severity and prognosis of $\mathrm{HF}^{[11,12]}$. In this context, it is not yet yielded whether isolated EVs from circulating progenitor cells, induced Pluripotent Stem Cells (iPSCs), human embryonic stem cells-derived CV progenitors (hESC-Pg) would be effective translators of reparative signals for cardiac repair.

There is evidence in support of cell-based therapies of HF with stem cells- and progenitor cell-derived EVs could have a promising impact on the regeneration of target organs in $\mathrm{HF}^{[6,13-15]}$. Kervadec et al (2016) ${ }^{[14]}$ reported that six weeks administration of EVs released by (hESC-Pg) in post-infarct HF model can provide equivalent benefits to administered hESC$\mathrm{Pg}$ and hESC-Pg and EV. The authors revealed that paracrine mechanism might be sufficient to effect functional recovery of target organs in ischemia-induced HF during cell-based therapy period. Adamiak et al (2018) ${ }^{[15]}$ revealed that iPSC-derived EVs demonstrated sufficient cytoprotective properties and induced cardiac repair associated with improved left ventricular function, attenuation of vascularization, and amelioration of cell apoptosis. There is evidence that the EVs received from cardiac progenitor cells, but not from fibroblasts, may improve global cardiac function after injury through suppression of cell apoptosis $^{[16]}$. Although an ability of the iPSC-derived CV progenitor cells differentiate in to $\mathrm{CV}$ lineages in vitro was found in early animal investigations ${ }^{[17-19]}$, there are limitations to translate their restoring capabilities (improvement of myocardial tissue and electrical function) into clinical practice due to uncertain efficacy in large clinical trials ${ }^{[20]}$. However, the cell therapies based on EVs isolation from target cells appears to be promising. Collectively, all these data confirmed the idea that the EVs are probably more optimal co-regulator of endogenous reparative activity of residential cells, neovascularization and enhancing endothelial function than other transplanted cells, such as iPSCs and endothelial precursors. Finally, whether cell therapies based on transplantation of iPSCs that may effectively differentiate into mature cardiac myocytes is superior to EVs received from pre-treated precursors or stem cells is not fully clear and requires more investigations in large clinical trials.

In conclusion, there is not strong evidence regarding clinical advantages of implanted EVs as an active component of the paracrine secretion by human cells to iPSCs in translation regenerative medicine in HF. However, the limitations of human iPSCs transplantation create expectations that EVs received from various cells could be safer and probably more effective than care based on pluripotent cell technologies.

Funding and Grants: This research received no specific grant from any funding agency in the public, commercial, or not-forprofit sectors.

Conflict of Interests: not declared

\section{References}

1. Hsu, J.J., Ziaeian, B., Fonarow, G.C. Heart Failure with MidRange (Borderline) Ejection Fraction: Clinical Implications and Future Directions. (2017) JACC Heart Fail 5(11): 763-771.

Pubmed |Crossref| Others

2. Sweitzer, N.K., Lopatin, M., Yancy, C.W., et al. Comparison of clinical features and outcomes of patients hospitalized with heart failure and normal ejection fraction ( $>$ or $=55 \%$ ) versus those with mildly reduced ( $40 \%$ to $55 \%)$ and moderately to severely reduced $(<40 \%)$ fractions. (2008) Am J Cardiol 101(8): 1151-1156.

Pubmed | Crossref | Others

3. Popovic, D., Arena, R., Guazzi, M. A flattening oxygen consumption trajectory phenotypes disease severity and poor prognosis in patients with heart failure with reduced, mid-range, and preserved ejection fraction. (2018) Eur J Heart Fail.

Pubmed |Crossref | Others

4. Berezin, A. Epigenetics in heart failure phenotypes. (2016) BBA Clin 6: 31-37.

Pubmed | Crossref | Others

5. Oikonomou, E., Mourouzis, K., Fountoulakis, P., et al. Interrelationship between diabetes mellitus and heart failure: the role of peroxisome proliferator-activated receptors in left ventricle performance. (2018) Heart Fail Rev 1-20.

Pubmed | Crossref | Others

6. Cabral, J., Ryan, A.E., Griffin, M.D., et al. Extracellular vesicles as modulators of wound healing. (2018) Adv Drug Deliv Rev.

Pubmed | Crossref | Others

7. Berezin, A. Metabolic memory phenomenon in diabetes mellitus: Achieving and perspectives. (2016) Diabetes Metab Syndr 10(2): S176-S183.

Pubmed | Crossref | Others

8. El, Harane, N., Kervadec, A., Bellamy, V., et al. Acellular therapeutic approach for heart failure: in vitro production of extracellular vesicles from human cardiovascular progenitors. (2018) Eur Heart J.

Pubmed | Crossref | Others

9. Berezin, A.E. Microparticles in Chronic Heart Failure. (2017)

Adv Clin Chem 81: 1-41.

Pubmed | Crossref $\mid$ Others

10. Durcin, M., Fleury, A., Taillebois, E., et al. Characterisation of adipocyte-derived extracellular vesicle subtypes identifies distinct protein and lipid signatures for large and small extracellular vesicles. (2017) J Extracell Vesicles 6(1): 1305677.

Pubmed | Crossref | Others

11. Berezin, A.E., Kremzer, A.A., Martovitskaya, Y.V., et al. The predictive role of circulating microparticles in patients with chronic heart failure. (2014) BBA Clin 3: 18-24.

Pubmed | Crossref | Others

12. Berezin, A.E., Kremzer, A.A., Berezina, T.A., et al. Pattern of circulating microparticles in chronic heart failure patients with metabolic syndrome: Relevance to neurohumoral and inflammatory activation. (2015) BBA Clin 4: 69-75.

Pubmed | Crossref | Others

13. Keerthikumar, S., Chisanga, D., Ariyaratne, D., et al. ExoCarta: A Web-Based Compendium of Exosomal Cargo. (2016) J Mol Biol 428(4): 688-692. 
Pubmed | Crossref $\mid$ Others

14. Kervadec, A., Bellamy, V., El, Harane, N., et al. Cardiovascular progenitor-derived extracellular vesicles recapitulate the beneficial effects of their parent cells in the treatment of chronic heart failure. (2016) J Heart Lung Transplant 35(6): 795-807.

Pubmed | Crossref | Others

15. Adamiak, M., Cheng, G., Bobis-Wozowicz, S., et al. Induced Pluripotent Stem Cell (iPSC)-Derived Extracellular Vesicles Are Safer and More Effective for Cardiac Repair Than iPSCs. (2018) Circ Res 122(2): 296-309.

Pubmed | Crossref | Others

16. Barile, L., Lionetti, V., Cervio, E., et al. Extracellular vesicles from human cardiac progenitor cells inhibit cardiomyocyte apoptosis and improve cardiac function after myocardial infarction. (2014) Cardiovasc Res 103(4): 530-541.

Pubmed | Crossref $\mid$ Others

17. Mauritz, C., Martens, A., Rojas, S.V., et al. Induced pluripotent stem cell (iPSC)-derived Flk-1 progenitor cells engraft, differentiate, and improve heart function in a mouse model of acute myocardial infarction. (2011) Eur Heart J 32(21): 2634-2641.

Pubmed | Crossref $\mid$ Others

18. Higuchi, T., Miyagawa, S., Pearson, J.T., et al. Functional and Electrical Integration of Induced Pluripotent Stem Cell-Derived Cardiomyocytes in a Myocardial Infarction Rat Heart. (2015) Cell Transplant 24(12): 2479-2489.

Pubmed | Crossref | Others

19. Ja, K.P., Miao, Q., Zhen, Tee, N.G., et al. iPSC-derived human cardiac progenitor cells improve ventricular remodelling via angiogenesis and interstitial networking of infarcted myocardium. (2016) J Cell Mol Med 20(2): 323-332.

Pubmed | Crossref | Others

20. Chung, E.S., Miller, L., Patel, A.N., et al. Changes in ventricular remodelling and clinical status during the year following a single administration of stromal cell-derived factor-1 non-viral gene therapy in chronic ischaemic heart failure patients: the STOP-HF randomized Phase II trial. (2015) Eur Heart J 36(33): 2228-2238.

Pubmed | Crossref $\mid$ Others
Submit your manuscript to Ommega Publishers and we will help you at every step:

- We accept pre-submission inquiries

- Our selector tool helps you to find the most relevant journal

- We provide round the clock customer support

- Convenient online submission

- Thorough peer review

- Inclusion in all major indexing services

- Maximum visibility for your research

Submit your manuscript at

https://www.ommegaonline.org/submit-manuscript 